\title{
Jornalismo ambiental, envelhecimento demográfico e Universidade Aberta à Terceira Idade: A tese do empoderamento
}

Pedro Celso Campos

\section{Resumo:}

A sociedade está envelhecendo. Esta pauta está presente, cada vez mais, na rotina dos meios de comunicação. Os futuros jornalistas devem ser sensibilizados para este fenômeno que envolve importante processo de mudança. Um dos caminhos pode ser o estudo das técnicas de empoderamento e formação de capital social, através das novas Tecnologias de Informação e Comunicacão (TIC), ou seguindo o exemplo das Universidades Abertas à Terceira Idade que estão surgindo em todo o mundo. Neste artigo estudamos o caso do Programa Universitário para Mayores, da Universidade de Sevilha (Espanha).

\section{Palavras Chave:}

Jornalismo, sociedade, mudança, terceira idade, ecologia, TIC.

\section{Abstract:}

The world is aging. This subject is becoming more and more present on the communication media. The future journalists must be made aware of this phenomenon that involves a important change in the society. One of the ways it can be the studied is through the empowerment and Social Capital Formation techniques, using the new Information and Communication Technologies (ICT), or following the example of the Universities Open to Senior Citizens that are appearing all over the world. In this article we'll study the case of the "Programa Universitario para Mayores" [University Program for the Elderly], at Seville University (Spain).

\section{Keywords:}

Journalism, society, change, senior citizens, ecology, ICT.

\section{"Reconhecer para conhecer" - Paulo Freire}

\section{Introdução}

As boas escolas de Comunicação estão permanentemente empenhadas em aperfeiçoar os seus cursos. O perfil de egresso esperado em todas elas corresponde a um profissional capaz de se sensibilizar com a complexidade dos fenômenos sociais à sua volta. Considerando o caráter eminentemente interdisciplinar que tal formação impõe, não seria possível tratar do tema aqui proposto sem convocar a vigorosa presença de estudiosos de áreas afins como a sociologia, a psicologia, a antropologia, a ecologia e, no caso específico deste (aparentemente inusitado) recorte sobre comunicação e terceira idade, algo de geriatria. Afinal, alguém já disse que o ideal mesmo seria os jornalistas também estudarem música clássica (para afinar o ouvido) e teatro (para aguçarem a percepção de conjunto)... Estamos diante de uma profissão enciclopédica e o grande perigo é abrir tanto o leque de conhecimentos que acabaremos não conhecendo coisa alguma e nos perdendo do principal que é o estudo da própria vida, a ponto de nos incluirmos no paradoxo de Pascal: "Onde está o saber que perdi com o conhecimento?" 
Neste artigo fazemos uma seleção de leituras sobre Empoderamento e Capital Social como conceitos da moderna sociologia que podem ser aplicáveis a um jornalismo socialmente comprometido, chamando atenção para as possibilidades oferecidas por algumas ferramentas da sociedade do conhecimento como as novas Tecnologias de Informação e Comunicação (TIC).

\section{Noção de Empoderamento}

A constatação de que determinados grupos sociais precisam de ajuda externa para se tornarem mais visíveis e respeitados na sociedade originou o termo "empoderamento", surgido, inicialmente, nos anos 1980, como "empowerment", na sociologia anglo-saxônica. Na época, tratava-se de explicar a ascensão da mulher na sociedade e no mercado de trabalho, assinalando um protagonismo que segue como motivo de luta em todo o mundo, naturalmente com avanços que variam em cada região. Em algumas sociedades, os direitos da mulher ainda não existem, infelizmente. Entidades que pesquisam o tema, como DAWN (1985), observam que o enfoque feminista de empoderamento das mulheres inclui tanto a mudança individual como a ação coletiva e envolve a alteração radical dos processos e estruturas que reproduzem a posição de subordinação da mulher como gênero. Mas já na década de 1960, Paulo Freire (1) trabalhava o conceito de pedagogia como libertação e na década de 1970 os pesquisadores do Banco Mundial passaram a aplicar tais ideais ao processo de desenvolvimento econômico e social, sobretudo na América Latina.

Na literatura hispânica, alguns autores, como Montero (2003), preferem a expressão "fortalecimiento" para explicar o mesmo conceito, definido como

processo mediante o qual membros de uma comunidade (indivíduos interessados e grupos organizados) desenvolvem conjuntamente capacidades e recursos para controlar suas condições de vida, atuando de maneira comprometida e crítica, para conseguir a transformação do seu ambiente conforme suas necessidades e aspirações, transformando-se ao mesmo tempo a si mesmos. (MONTERO, 2003)

É uma definição concorde com o Dicionário Pan-Hispânico de Dúvidas que acusa o uso do termo empoderamento em textos de sociologia política com o sentido de "conceder poder a um grupo de pessoas desfavorecido socioeconomicamente, para que melhore suas condições de vida através de suas próprias ações".

O empoderamento também é visto como um processo de construção social que relaciona forças individuais e capacidades (competência), sistemas naturais de ajuda e condutas pró-ativas com assuntos de mudança social e política social (ZIMMERMAN, 2000; RAPPAPORT, 1998 apud SILVA; MARTINEZ, 2004), que se desenvolve em três níveis: individual, organizacional e comunitário.

Em nível individual, os processos de empoderamento podem ser alcançados através da participação em organizações ou atividades comunitárias, integrando grupos de trabalho, aprendendo novas tarefas, desenvolvendo novos potenciais etc. O próprio fato de trabalhar em equipe, perseguindo metas comuns, já pode ter um potencial empoderador, do ponto de vista disciplinar. Esse processo pode ser ativado por animadores externos como agentes sociais, ONGs, mentores, líderes de grupo, professores etc., que atuam de forma a prover oportunidades para as pessoas exercerem controle sobre suas vidas, podendo elas mesmas formarem novos grupos empoderadores, num processo solidário e continuado de formação cidadã. Esse processo sofre influências diretas (positivas ou negativas) do contexto social, isto é, do entorno ecológico no qual se desenvolve. Naturalmente, no ambiente favorável, em que a sociedade, o poder público, as entidades organizadas e outras estão voltadas para a inclusão social, o processo de 
empoderamento prosperará de modo mais eficaz.

Ao tratar do nível organizacional do empoderamento, Zimmerman (2000) destaca a importância de se desenvolver a noção de "pertencimento", de "sentir-se parte do grupo", de "ser equipe", pois é essa noção de pertença que legitima e fortalece o grupo. Aqui sobressai o papel da comunicação como agregadora dos sujeitos sociais, ajudando a criar um ambiente favorável em busca das metas propostas. O comunicador precisa estar consciente de que sua atuação é fundamental na coesão interna do grupo e na busca de apoios que ele precisa para ter visibilidade e resultados. Trata-se, portanto, de fortalecer a organização como um todo, no marco teórico da teoria de difusão de informações que estabelece: "Um adequado fluxo de informação e uso apropriado dos meios de comunicação de massa podem contribuir para mudar os hábitos dos indivíduos". Mas a comunicação em si não é capaz de mudar a realidade. A mudança só ocorre a partir da motivação individual. A comunicação pode reforçar as técnicas de empoderamento do grupo social. Em muitas situações, isto significa colocar em marcha processos de liderança compartilhada, processos de capacitação de membros em função dos objetivos da organização, processos de tomada de decisões, sistemas de distribuição de funções e responsabilidades conforme a capacidade de cada um, criação de mecanismos de intercâmbio de informações e recursos, um modelo ou estilo de gestão adequada em função do crescimento e desenvolvimento da organização. Naturalmente nada disto é atingível se todo o grupo não estiver imbuído dos mesmos objetivos, se não for solidário, se não houver respeito, confiança e tolerância.

O nível comunitário do empoderamento resulta dos dois níveis anteriormente citados. Quando se conta com indivíduos interiormente empoderados e organizações voltadas para o empoderamento, então se pode falar em comunidades empoderadas que defendem os seus direitos, que se interessam pelo bem coletivo, que se solidarizam com o semelhante, que lutam pela inclusão social de modo a empoderar outros grupos, que têm visão crítica sobre as injustiças sociais e econômicas em nível local e mundial, que respeitam o meio ambiente etc. Speer e Hughey (1995) observam que o empoderamento a nível comunitário implica no desenvolvimento de redes intersetoriais de organizações e instituições da comunidade local. Essa cooperação, mediante a troca de informação e experiência, levando em conta todos os agentes dentro do enfoque ecológico descrito por Edgard Morin, é determinante para o bem estar de toda a comunidade, na mesma medida em que a participação individual é que vai enriquecer e fortalecer as organizações empoderadoras. A intenção é evidenciar o caráter eminentemente sistêmico do processo de empoderamento. Nem mesmo o professor, ou líder de grupo, ou mentor poderá estar só na sua tarefa de empoderar. Paulo Freire lembra que ninguém ensina ninguém, pois o processo de aprender é recíproco. Assim, na comunidade empoderada também haverá uma acentuada noção de democracia interna, de horizontalidade de mando, de modo tal que todos possam ser ouvidos com respeito. Essa inter-relação das pessoas no grupo, do grupo na comunidade, da comunidade no sistema-mundo, nos conduz a outro modo de ver o nosso mundo e o mundo em si, num processo ecológico em que estamos todos integrados entre nós mesmos e com a natureza da qual somos parte indissociável e da qual dependemos para viver. No futuro mundo de comunidades empoderadas, isto é, de comunidades que participam igualitariamente do banquete da vida, sem exclusões, não há lugar para a violência e a guerra. A comunicação é central nesse processo de conscientização política e cidadã. Com efeito, a hipótese inicial da teoria difusionista diz que "a combinação de meios de comunicação de massa e estratégias de comunicação interpessoal (caráter sistêmico) podem favorecer a mobilização individual para a adoção de novos meios de produção através de um processo de abertura, interesse, avaliação e adoção de tecnologia".

Retornando a Zimmerman, dos três níveis citados, emerge um questionamento: O que é mais importante, o empoderamento individual, organizacional ou comunitário? Os psicólogos transpessoais, entre eles Ken Wilbur, Michael Washburn, Stanislav Grof (conf. CAPRA, 1988) assinalam que a transformação interna resultante do empoderamento individual está muito ligada a um espírito de comunidade, de solidariedade humana. À medida que a pessoa passa a se conhecer, a aceitar-se e a amar-se a si mesma, ela começa a 
aceitar e amar o outro, uma vez que pode ver a si mesma no outro. Assim, o empoderamento individual promove a solidariedade, uma auto-definição pessoal baseada no sentido de pertencimento a uma comunidade maior, universal, cósmica e não como indivíduo egoisticamente isolado.

No empoderamento de nível transpessoal, pelo fortalecimento interno do sujeito, há uma sensação automática de solidariedade com todos os viventes, um sentido de compaixão pelo excluído, acompanhado pelo deslocamento da mentalidade temerosa e avara do "eu primeiro" que é norma do capitalismo, a uma mentalidade de maior plenitude ("viver e deixar viver"), uma confiança de que "já tenho o suficiente". Esse ponto de vista da psicologia transcendental e dos sociólogos transpessoais sobre empoderamento está muito próximo dos pontos de vista de muitas tradições espirituais do mundo antigo. Modernamente, Fromm, o jovem Marx e Ghandi criticaram a ênfase hegemônica do desenvolvimento no "ter" mais que no "ser" (SILVA; MARTINEZ, 2004).

Segundo McLaughlin e Davidson (apud SILVA; MARTINEZ, 2004), "o empoderamento baseado na transformação interior motiva a pessoa a melhorar não só sua própria vida, mas também a vida dos demais", enquanto Lape e DuBois (1984) afirmam que

o empoderamento individual se manifesta na conscientização e participação política - um sentido de militância baseado não em um pequeno interesse pessoal, tão pouco em sentir-se vítima, nem em lançar a culpa nos demais, mas no sentido maior de comunidade e responsabilidade. Com a participação, crescem as habilidades políticas (LAPE; DUBOIS, 1984).

A teoria do empoderamento ensina que todos e cada um têm poder de transformação, de superação. O empoderamento nos transforma em sujeitos da história, pessoas que transformam seu ambiente ao invés de serem transformadas por ele. O empoderamento individual traz a força de cada um à mesa de negociação por um mundo melhor, por uma vida mais digna. Mas não há jogo sem jogadores. E não basta participar, é preciso se envolver, se comprometer, jogar-se por inteiro.

Assim, é tão importante o empoderamento individual quanto o organizacional e o comunitário, mas nada se consegue se as pessoas não se dispuserem a colaborar, disciplinadamente, pois não se trata de um bem que se pode dar, mas sim de um processo induzido, amplo e vagaroso no qual as próprias pessoas participantes são protagonistas através de seus esforços individuais e coletivos. Por isto é importante que o processo seja organizado horizontalmente, pela própria sociedade, atuando diretamente junto aos grupos e segmentos envolvidos de modo que alcancem seus objetivos com a união do grupo e não com poderes outorgados por outros quase sempre com segundas intenções, para tirar proveito político etc.

Granovetter (1985), Bourdieu (1989), Evans (1996), Durston (2000) e Romano (2002) concordam que o empoderamento envolve Auto-confiança (para fugir da apatia, ser atuante, acreditar na causa, alimentar o otimismo); Capacidade Crítica (para perceber, no entorno, quais são os problemas a serem analisados e superados); Participação (reunir-se, dialogar, agir, manifestar-se); Organização (estudar, aprender, abrirse ao novo conhecimento, às novas tecnologias, doar-se ao coletivo); Solidariedade (no sentido de generosidade, alteridade, aceitação das diferenças) e Capital Social (constituir-se como ser pensante e crítico para conduzir sem ser conduzido).

\section{Capital Social}

O empoderamento é capaz de elevar o nível de "capital social" (CS), ou de participação cidadã na sociedade civil, de um grupo, ou de uma comunidade. Para Pierre Bourdieu (1983: 249), "capital social é a agregação de recursos reais ou potenciais que estão ligados à posse de uma rede durável de relações mais ou menos institucionalizadas de conhecimento mútuo e de reconhecimento" (grifo nosso). Distingue 
três formas de CS: econômico, cultural e social, chamando atenção para a desigualdade de acesso aos recursos. Para Bourdieu as novas tecnologias acabam favorecendo sempre mais as elites que são, naturalmente, contrárias à formação de capital social nas democracias abertas onde existe, por exemplo, liberdade de expressão.

A observação de Bourdieu põe em destaque o papel do ativismo político a favor das classes excluídas, cabendo ao jornalismo socialmente comprometido dar voz a esses setores e colaborar com o seu empoderamento. Também Paulo Freire insiste que só o reconhecimento traz o conhecimento, só a atitude humilde diante do saber pode conduzir ao saber em si, um conceito valiosíssimo para o jornalista interessado em conferir exaustivamente a informação recebida antes de publicá-la, no marco da ética que a profissão requer e exige.

Em Coleman's (1994: 302) aprendemos que “o capital social é definido por sua função. Não é uma entidade única, mas uma variedade de diferentes entidades, com duas características em comum: todas elas consistem em algum aspecto de uma estrutura social e facilitam certas ações de indivíduos que se encontram dentro da estrutura". Coleman's acha que a formação de capital social, embora favorecendo as elites como ensina Bourdieu, também está acessível às comunidades carentes e aos grupos excluídos da sociedade, desde que venha a contar com motivação e apoio neste sentido. Novamente se vê aqui a importância da comunicação quando ela se coloca a serviço da sociedade e não apenas de grupos políticos, ideológicos ou de governos. A pesquisa de Coleman's realça, igualmente, o papel da família, das relações de parentesco e das instituições religiosas na formação de capital social.

Para os pesquisadores do Banco Mundial, quando falamos em CS estamos nos referindo às instituições, relações e normas que definem a qualidade e a quantidade de interações sociais em uma comunidade. $\mathrm{O}$ CS não é apenas a soma das instituições que constituem elementos essenciais de uma sociedade, é a "liga", a "cola" que cimenta essas relações, que as mantém unidas e coesas.

Entre os estudos mais citados, nos últimos anos, sobre CS está o de Robert Putnam que, a partir das teorizações de Coleman's e Bourdieu, mapeou os níveis de participação cívica nos Estados Unidos e constatou acentuado declínio nas últimas três décadas do milênio. Sua pesquisa foi publicada no livro "Bowling Alone", em 2000. Esta é sua definição de CS:

Considerando que o capital físico se refere a objetos físicos e no capital humano refere-se às propriedades dos indivíduos, o capital social refere-se às ligações entre os indivíduos, às redes sociais e às normas de confiança e reciprocidade que surgem a partir dessas ligações. Neste sentido o capital social está intimamente relacionado com o que alguns têm chamado de "virtude cívica'. A diferença é que o capital social é mais poderoso quando incorporado em um sentido rede de reciprocidade das relações sociais. A sociedade de indivíduos isolados, embora muito virtuosos, não é, necessariamente, rica em capital social (Putnam, 2000: 19).

Putnam constatou uma diminuição significativa na quantidade de americanos que participam de organizações religiosas, atividades cívicas, recreativas, clubes e outras iniciativas coletivas (como jogar vôlei) com um correspondente aumento de atividades individualizadas (principalmente ver televisão). Em sua pesquisa, os indicadores de conhecimento político, confiança na classe política, ativismo político e atuação em bases populares estão todos para baixo. Os americanos estão assinando $30 \%$ menos petições e revelam $40 \%$ menos disposição de participarem de um boicote de consumidores em comparação com uma ou duas décadas atrás. Em meados da década de 1970 o americano médio frequentava clubes todos os meses. Em 1998 essa participação havia caído quase 60\%. Em 1975 as reuniões com amigos chegavam a 15 encontros por ano, em 1998 caíram pela metade. O trabalho observou, igualmente, que embora os americanos se revelem mais tolerantes uns com os outros em relação a gerações passadas, eles confiam 
menos uns nos outros. Os dados mostram esse crescimento da desconfiança mútua, da desonestidade. Há mais reclamações à polícia e aos tribunais, o que provocou a elevação do número de advogados, policiais e pessoal de segurança, lembrando o pesquisador que durante a maior parte do século tais atividades estavam estagnadas, a ponto de a América ter menos advogados per capita em 1970 do que tinha em 1900. A conclusão de Putnam é que isto enfraqueceu o capital social do país. Dessa forma, poderosos meios de comunicação, como a TV ou a internet, ao invés de contribuírem para o empoderamento das pessoas e dos grupos sociais, estariam atuando em sentido contrário.

Nem todos os estudiosos concordam com a teoria de Putnam. Não se poderia atribuir à televisão o papel de mudar totalmente a sociedade, ainda que pesem as críticas gerais contra o conteúdo da programação de TV mais voltado para o espetáculo e a força da imagem. Theda Skocpol (2003), ao criticar o trabalho de Putnam, observa que as alterações mais significativas na sociedade atual referem-se à mudança da forma associativa de vida. Ela questiona o excesso de ênfase no trabalho de Putnam e outros sobre o funcionamento dos grupos locais e das associações. "O voluntariado cívico nunca foi predominantemente local nos Estados Unidos e nunca se desenvolveu para além do governo nacional e da política. Os teóricos do capital social têm a tendência de analisar todas as formas de participação de uma só vez" (Skocpol, 2003: 12). Ela sugere que uma confluência de tendências e eventos gerou uma mudança de adesão à mobilização geral em forma de organizações cívicas. Segundo ela, depois de 1960, época de mudanças nos ideais raciais e de gênero, um novo tipo de relacionamento empurrou as lideranças dos públicos masculino e feminino para novas direções. Novas oportunidades e desafios políticos atraíram recursos e ativistas cívicos em direção aos lobbies centralizados. As novas tecnologias e fontes de apoio financeiro permitiram a constituição de novos modelos de associativismo. Finalmente, mudanças na estrutura e nas classes elitistas americanas criaram um círculo mais amplo para organizações profissionalmente geridas. Agora os americanos mais privilegiados podem se organizar virtualmente (Skocpol 2003: 178).

Outra contribuição significativa ao trabalho de Putnam veio de Ann Bookman (2004). Ela acha que não se pode falar em capital social, hoje, sem levar em conta o papel da mulher na sociedade que teria um capital social "acumulado" ao desempenhar duplas jornadas como profissional e mãe de família. Novas formas de CS estão se desenvolvendo, entre famílias que trabalham em ambientes urbanos e suburbanos - como no caso dos cuidadores de crianças e idosos, os empregados domésticos etc.

De todo modo o trabalho de Putnam deixa claro que a formação de capital social traz inúmeras vantagens. Ele cita, por exemplo, o desenvolvimento das crianças, através do melhor aproveitamento escolar e, consequentemente, do comportamento e desenvolvimento futuro, quando a família dá ao acompanhamento da formação escolar o destaque que ele merece. Mostra que é perceptível a redução no índice de criminalidade nas comunidades onde os jovens estão interligados por redes de amigos e participam de atividades comuns. Diz que o CS pode ajudar a atenuar os efeitos insidiosos da desvantagem socioeconômica, quando uma nação, uma sociedade ou mesmo um grupamento de pessoas, ou de empresas, se organizam para formar capital social através do florescimento de redes sociais, mediante técnicas de empoderamento. Ele também vê uma relação entre CS e boa saúde, ao observar que cai pela metade o risco de morte entre pessoas que vivem em grupo em relação a pessoas que vivem isoladas, solitárias. No grupo, a pessoa acaba sendo ajudada a desenvolver hábitos mais saudáveis como deixar de fumar, fazer exercícios, sair de casa, alimentar-se melhor, cuidar dos medicamentos etc. Para ele, a assiduidade a um clube, a participação em trabalhos voluntários, a recreação, a frequência à Igreja equivalem, para a pessoa que antes vivia só, à felicidade de receber um diploma acadêmico ou ter o salário duplicado. Pode-se ter uma vida rica e feliz sem ter riqueza material, ensina.

\section{Meios de Comunicação}

Este artigo tem o objetivo de relacionar o papel social dos meios de comunicação com sua capacidade de 
contribuir para o empoderamento e, consequentemente, para a elevação do capital social nas comunidades. Muito embora as técnicas de formação de capital social sejam aplicáveis a todas as pessoas e grupos sociais, faremos aqui um recorte no segmento de público que mais tem crescido nos últimos tempos e que vai se tornando, cada vez mais, uma pauta de abordagem diária para a imprensa. Trata-se do segmento das pessoas idosas e do fenômeno global do envelhecimento demográfico, tema, aliás, pouco tratado na área acadêmica, o que parece confirmar o modo paternalista e assistencialista como é vista a pessoa idosa na sociedade, como se não tivesse ou não pudesse ter qualquer papel social. Igualmente é importante lembrar que o idoso é, hoje, um consumidor urbano de notícias e informações, ao contrário de algumas décadas atrás quando ainda existiam comunidades rurais e as tecnologias de informação limitavam-se praticamente ao rádio.

O mundo do século XXI será, em grande parte, urbano. Nos países em desenvolvimento, a população urbana decuplicou em apenas 65 anos, passando de 100 milhões em 1920 a 1 bilhão em fins do século. Considerando o conjunto da humanidade, hoje com 6,5 bilhões de pessoas - onde se inserem os problemas ecológicos e ambientais, inclusive questões prementes como a mudança do clima e o envelhecimento demográfico - os planejadores levam em conta dados da Organização das Nações Unidas (ONU) segundo os quais a população poderia se estabilizar entre 8 e 14 bilhões de habitantes em algum momento do século XXI. É importante registrar que $90 \%$ desse crescimento populacional ocorrerá nos países mais pobres, conforme o documento da ONU "Nosso Futuro Comum". Isto significa que os países mais desenvolvidos também terão as populações mais idosas do mundo. De fato isto já vem ocorrendo. Até meados do século XVIII, a esperança de vida nos países europeus rondava os 30 anos. No ano 2000 era de 77 e está subindo (SEMPERE; RIECHMENN,2000: 191). No Japão atual é de 85 anos. Em 2050 dois em cada cinco japoneses terão mais de 65 anos, somando-se a uma população superior a dois bilhões de idosos em todo o mundo, segundo projeções da ONU. A Tabela 1, a seguir dá uma idéia da situação. É possível, observar, por exemplo, que apesar da longevidade estar crescendo também nos países pobres, a sobrevida segue elevada proporcionalmente à qualidade de vida do país onde vive o idoso. Assim, na faixa superior a 80 anos, os percentuais de sobrevida vão se reduzindo drasticamente nas regiões mais pobres, se comparadas com as regiões mais ricas do planeta. Enquanto na Alemanha (15,3\%) e no Japão $(15,2 \%)$ a Quarta Idade mantém representação expressiva na população, em outros países como Índia $(3,3 \%)$, México $(2,4 \%)$ e Nigéria ( $0,7 \%)$ esse segmento é cada vez menor.

Tabela 1. Paises com maior envelhecimento, 2000-2050

\begin{tabular}{|c|c|c|c|c|c|c|c|c|c|}
\hline & \multicolumn{4}{|c|}{$\begin{array}{c}\text { População com } 65 \text { anos ou } \\
\text { mais }\end{array}$} & & \multicolumn{4}{|c|}{$\begin{array}{c}\text { População com } 65 \text { an os ou } \\
\text { mais }\end{array}$} \\
\hline & \multicolumn{2}{|c|}{2000} & \multicolumn{2}{|c|}{2050} & & \multicolumn{2}{|c|}{2000} & \multicolumn{2}{|c|}{2050} \\
\hline & $\begin{array}{l}\text { número } \\
\text { (mil) }\end{array}$ & $\%$ & $\begin{array}{l}\text { número } \\
\text { (mil) }\end{array}$ & $\%$ & & $\begin{array}{l}\text { número } \\
\text { (mil) }\end{array}$ & $\%$ & $\begin{array}{l}\text { número } \\
\text { (mil) }\end{array}$ & $\%$ \\
\hline Itália & 10.525 & 18,2 & 18.090 & 35,5 & Reino Unido & 2.390 & 4,1 & 5.885 & 8,8 \\
\hline Japão & 21.862 & 17,2 & 40.269 & 35,9 & Itália & 2.309 & 4,0 & 7.756 & 15,2 \\
\hline Espanha & 6.797 & 16,7 & 14.504 & 34,1 & França & 2.341 & 3,9 & 6.863 & 10,9 \\
\hline Alemanha & 13.483 & 16,4 & 22.376 & 28,4 & Japão & 4.812 & 3,8 & 17.159 & 15,3 \\
\hline França & 9.669 & 16,3 & 17.114 & 27,1 & Alemanha & 2.859 & 3,5 & 9.585 & 12,2 \\
\hline Reino Unido & 9.306 & 15,9 & 15.558 & 23,2 & Espanha & 1.413 & 3,5 & 5.213 & 12,3 \\
\hline Ucrânia & 6.863 & 14,0 & 7.689 & 29,1 & EUA & 9.138 & 3,2 & 28.725 & 7,3 \\
\hline Rússia & 18.081 & 12,3 & 25.747 & 23,0 & Ucrânia & 1.107 & 2,3 & 2.075 & 7,9 \\
\hline EUA & 35.078 & 12,3 & 81.547 & 20,6 & Rússia & 2.935 & 2,0 & 6.588 & 5,9 \\
\hline China & 87.228 & 6,8 & 329.103 & 23,6 & Brasil & 1.624 & 0,9 & 13.989 & 5,5 \\
\hline Vietnam & 4.251 & 5,4 & 21.712 & 18,6 & China & 11.373 & 0,9 & 100.551 & 7,2 \\
\hline Brasil & 9.457 & 5,4 & 48.693 & 19,2 & México & 854 & 0,9 & 8.002 & 5,8 \\
\hline Indonésia & 10.236 & 4,9 & 49.670 & 17,4 & Vietnam & 671 & 0,9 & 5.082 & 4,4 \\
\hline India & 50.054 & 4,9 & 236.513 & 14,8 & India & 6.761 & 0,7 & 52.915 & 3,3 \\
\hline México & 4.759 & 4,8 & 29.371 & 21,1 & Egito & 320 & 0,5 & 3.077 & 2,4 \\
\hline Egito & 3.027 & 4,5 & 16.727 & 13,3 & Indonésia & 1.092 & 0,5 & 9.492 & 3,3 \\
\hline Paquistão & 5.261 & 3,7 & 31.119 & 10,2 & Paquistão & 652 & 0,5 & 5.651 & 1,9 \\
\hline Bangladesh & 4.370 & 3,4 & 28.240 & 11,6 & Bangladesh & 479 & 0,4 & 4.595 & 1,9 \\
\hline Nigéria & 3.495 & 3,0 & 14.726 & 5,7 & Nigéria & 359 & 0,3 & 1.910 & 0,7 \\
\hline
\end{tabular}

Fonte: ONU: Worid Population Prospects: The 2004 Revision. ONU, consultado em junho de 2006 
Perante esses dados, parece correto supor que os meios de comunicação, notadamente os Novos Meios de Informação e Comunicação (NOMIC), sem abrir mão dos meios tradicionais, têm muito a contribuir nessa tarefa de dar visibilidade social aos grupos excluídos - neste caso, ao segmento dos idosos - sempre que estivermos falando de um jornalismo socialmente comprometido.

Diversos autores observam, entretanto, que as novas tecnologias de comunicação não estão cumprindo adequadamente esse papel de servir à sociedade. No caso da TV Digital, por exemplo, a constatação é que, em vários países, o telespectador obtém uma excelente melhoria na qualidade da imagem, mas as funções interativas ficam apenas no plano econômico, facilitando o acesso do consumidor aos mais variados produtos que podem ser adquiridos instantaneamente. Quase nada se avança na possibilidade de interferir nos conteúdos ou, o que é mais importante, de abrir canais de participação direta para os grupos sociais como permite a tecnologia digital. O resultado é que os meios de comunicação continuam concentrados em poucas mãos, inviabilizando a esperada democratização que abriria o acesso às novas tecnologias a todas as pessoas.

Ainda que os estudos de Putnam não tenham conseguido comprovar a relação entre "ver televisão" e "não participar" da comunidade, ou não se sentir "parte" dela, o fato é que os conteúdos da mídia têm grande influência sobre os grupos sociais e sobre as pessoas. A este respeito, Wolf (1995) afirma: "As novas formas de comunicação eletrônica debilitam as mais consolidadas instituições produtoras e reprodutoras de identidade social, como a escola, os grandes meios nacionais de comunicação ou as igrejas". É curiosa a observação de que a mídia eletrônica acaba debilitando a mídia tradicional - no caso, a mídia impressa. Com efeito, por sua preocupação com a imagem, a TV acaba sendo bem mais superficialista que os jornais em seu noticiário. E fora dos telejornais, a TV, tanto quanto a internet, acaba levando para dentro da casa das pessoas uma razoável quantidade de informações inúteis, quando não inverídicas, como acontece nos programas que o Brasil conhece como "fofoca" e a Espanha chama de "TV Corazón". Naturalmente é preciso fazer uma menção aos tablóides ingleses e outros semelhantes que abrem larga vantagem nesse tipo de jornalismo inútil e alienante.

$\mathrm{Na}$ verdade as novas tecnologias, embora colocadas muito mais a serviço do próprio capital (e aqui não é social) do que da sociedade, estão alterando o próprio sentido da palavra "comunicação". A debilitação da identidade de que fala Wolf, e já antes analisada por Walter Benjamin, é causada por um sentido de "perda de espaço", de "desterritorialização" que é próprio do mar global de notícias e informações no qual estamos inseridos através dos mais diferentes suportes tecnológicos. É o que ocorre, por exemplo, no caso da telefonia móvel. O telefone fixo tradicional limitava a conversação a espaços sociais específicos (a intimidade do quarto, a privacidade da sala de estar, o âmbito profissional do escritório etc.) e, portanto, a expectativas determinadas de conversação. A telefonia móvel, ao contrário, desterritorializa o usuário desses espaços e transforma radicalmente o sentido do entorno e do instantâneo: o próximo e o distante podem ser redefinidos todo o tempo, a acessibilidade a uma telecomunidade virtual isola o sujeito da situação imediata, o espaço profissional se dispersa, o lazer e o negócio se confundem, de tal modo que comunicar-se, hoje, significa construir e gerir, de forma contínua, entornos contingentes (Abril, 2003:16).

Por outro lado, a modernização dos suportes de comunicação não deveria ser motivo de conduzir as pessoas a um processo de "incomunicação", de isolamento social. Deveria, pelo contrário, maximizar os efeitos comunicativos. Não por acaso, ao considerar a possibilidade de uma "ética racional", Weber (1964) contrapõe-se ao seu próprio pessimismo, segundo o qual de um mundo totalmente racionalizado só se pode esperar o encarceramento do homem pelos procedimentos técnicos e burocráticos. No caso do jornalismo, especificamente, é preciso que se mantenha o necessário envolvimento com as comunidades, físicas ou virtuais, sem eximir-se da responsabilidade social e do serviço público que é inerente a esta profissão. Seria de todo conveniente, no mundo ideal, claro, que as empresas particulares produzissem material jornalístico como se fossem empresas públicas, visando mais a prestação de serviços à sociedade 
que o lucro. Nesta dimensão, vale registrar o pensamento do professor da Faculdade de Comunicação da Universidade de Sevilha, Francisco Sierra Caballero:

La lógica de servicio público plantea un reto estratégico para la mediación informativa: la estructuración comunitaria y la contribución de los informadores a la integración y desarrollo social equilibrado. Desde este punto de vista, la comunicación pública debe atender al menos las siguientes consideraciones: 1. Las necesidades sociales (educación, expresión, vivienda, salud, medios de reproducción en general); 2. El cambio de horizontes y perspectiva social; 3 . El pluralismo ideológico, cultural, político-social y geográfico; 4. El desarrollo de las identidades singulares; 5. El diálogo público y la ética ciudadana; 6. La articulación de redes sociales solidarias para una cultura cívica responsable con la comunidad (SIERRA, 2006).

Entretanto, levando em conta o caráter de "produto à venda" da notícia, em todos os suportes técnicos, considerando também a centralização dos meios, e tendo em vista a necessidade de um jornalismo voltado para os interesses comunitários da sociedade, que ajudem a formar capital social, é de grande valia registrar outra observação do professor Sierra:

Os movimentos sociais e as ONGS devem redefinir suas lutas pela visibilidade construindo outras imagens e formas de rearticulação do espaço público, apostando em redes locais, radicalmente descentralizadas por bairros e comprometidas em processos globais de democratização e desenvolvimento social. A partir dos coletivos locais, organizados autonomamente, mas organizados em rede, é preciso maximizar a criatividade cultural e a produção de conhecimento segundo o método: Comunicação, Colaboração, Coordenação e Ação Social Solidária.

Trata-se, com efeito, de pensar a sociedade dentro de um horizonte de compreensão, no sentido weberiano, olhando-a como uma conexão de ações dotadas de significado subjetivo atribuído pelo agente, ou agentes, que se encadeiam em relações sociais.

Com criatividade, o comunicador consciente de suas responsabilidades sociais pode sugerir pautas no veículo de comunicação onde trabalha ou pode explorar os espaços comunitários do jornalismo, tanto na mídia impressa - através de jornais com públicos geograficamente definidos - ou através das comunidades virtuais, pela internet. Também é possível utilizar os jornais alternativos já existentes, como é o caso, no Brasil, do jornal do Movimento dos Trabalhadores Sem Terra (MST). Na internet muitas ONGs abrem espaço à participação popular em seus portais. Na América Latina, particularmente, os jornalistas têm poucas alternativas, a não ser insistir-se nesses recursos, tendo em vista que a mídia está cada vez mais monopolizada pelo capital. Na conferência de abertura no VI Congresso de la Associación Latinoamericana de Investigadores de la Comunicación, em Santa Cruz de la Sierra (Bolívia), em 2002, disse o professor venezuelano Antonio Pasquali:

A América Latina é a única região da terra com uma radiotelevisão monoliticamente comercial e, portanto, desinteressada em componentes desenvolvimentistas, culturais, sociais e democratizadores. Torna-se, pois, imperativo modificar, pelo menos um pouco, o regime de posse e uso dos sinais de freqüência para gerar empregos não lucrativos, com três propósitos essenciais: 1. Garantir um mínimo democrático de pluralismo comunicacional; 2. Salvaguardar o que a UNESCO define como "a fecunda diversidade das culturas"; 3. Assegurar a sobrevivência de alguma indústria cultural endógena.

Também para Pasquali, a exemplo de Sierra Caballero, a estratégia mais apropriada seria fomentar a comunicação comunitária e garantir, a nível macro, a existência de serviços radiotelevisivos públicos para impedir que os usuários continuem sem opção, sem alternativas entre o veículo público oficial e o privado 
mercantilizado. Parece válido considerar que um veículo comunitário pode ter uma influência maior no estímulo à cidadania e, portanto, na formação de capital social, constituindo-se, portanto, em valiosa ferramenta de empoderamento individual e de grupos.

O que salva, em toda esta situação é que, muitas vezes, na busca desenfreada do lucro, o capitalismo acaba flanqueando alguns espaços que a sociedade organizada pode explorar. Um exemplo claro é o apoio que a Comissão Européia vem dando ao desenvolvimento de novos produtos midiáticos na área das Tecnologias da Informação e da Comunicação (TICs). Desde 2007 até 2013 a União Européia e os EUA, junto com o setor privado, investirão mais de um bilhão de euros em pesquisa e inovação dentro do programa "Envelhecer bem na Sociedade da Informação". Apesar dos objetivos econômicos, o programa está organizado em normativas que podem contribuir com a inclusão social, tais como: 1. Uma Sociedade da Informação aberta a todos (IP/05/643); 2. Uma Sociedade da Informação aberta ao crescimento e ao emprego (IP/05/643); 3. Acessibilidade Eletrônica (IP/05/1144); 4. Uma agenda política de inclusão digital, conforme acordado em 2006 pelos Estados-Membros reunidos em Riga (IP/06/769) e para o final de 2007 estava prevista uma comunicação relativa à estratégia da União Européia em inclusão digital.

Da verba total, 600 milhões de euros são destinados ao programa "Vida Quotidiana Assistida pela Comunidade"; 400 milhões de euros destinam-se ao recente Programa Marco de pesquisa da União Européia (IP/06/1590) e 30 milhões foram aplicados em 2007 no Programa de Apoio à Política em matéria de TIC (IP/06/716). O objetivo, segundo o site da UE, é "criar uma sólida base industrial na Europa para as Tecnologias da Informação e da Comunicação e o envelhecimento. A própria Europa poderia converter-se em um mercado referencial das TICs para um envelhecimento melhor. Posto que o envelhecimento é um fenômeno mundial, uma indústria européia forte significaria oportunidade em todo o mundo". Ao lançar o plano em junho de 2007 em Bruxelas, a Comissária Européia de Sociedade da Informação e Meios de Comunicação, Viviane Reding, disse que "as Tecnologias de Informação e Comunicação proporcionarão novos produtos e serviços mais acessíveis que respondam às necessidades de nossos idosos", lembrando que a pesquisa voltada para o desenvolvimento de aplicações mais práticas e simples, de mais fácil compreensão e utilização, tem um âmbito de aplicação muito mais amplo.

Dessa forma, atraindo os empresários para o negócio, a Comissão Européia contribui, de modo substancial, para chamar a atenção da sociedade para o fenômeno do envelhecimento demográfico que, do ponto de vista ecológico, é tão importante quanto a mudança do clima e, no entanto, não vem sendo tratado com a devida seriedade, uma vez que parece estranho falar de "envelhecimento" na sociedade do conhecimento permeada por bens simbólicos que remetem a um mundo freneticamente high tech, sem tempo ou sem espaço para reflexões. Resulta claro, todavia, que os investimentos em TICs também podem ser canalizados para o empoderamento de pessoas e grupos sociais visando a elevação do capital social, mesmo que não seja esta a intenção primeira da elite econômica que centraliza os meios de comunicação. O documento da União Européia reconhece que a maioria dos idosos ainda não se beneficia das vantagens da era digital, por exemplo, e que só $10 \%$ deles, na Europa, utilizam a Internet. O programa da UE defende "comunicações de baixo custo e serviços on line especialmente dirigidos aos idosos, o que poderia aliviar suas limitações de locomoção, além de poder gerar até mesmo um mercado virtual para o trabalho do idoso no lar. Conforme o documento, "os graves problemas de visão, audição ou destreza frustram com freqüência os intentos de $21 \%$ das pessoas de mais de 50 anos que tentam integrar-se na sociedade da informação". Trata-se de uma situação que realmente demanda algum tipo de atenção - não só na Europa, mas em todo o mundo - pois, conforme os levantamentos que deram origem ao programa da UE para envelhecer bem, "em 2020, 25\% dos cidadãos da União Européia terão mais de 65 anos. Calcula-se que o gasto com pensões, assistência à saúde e cuidados de longa duração aumentarão de $4 \%$ a $8 \%$ do Produto Interno Bruto-PIB, nos próximos decênios e em 2050 o gasto total triplicará”.

O objetivo do programa de apoio às TICs é a formatação de programas, inclusive na área da 
Comunicação, que ajudarão cada vez mais as pessoas idosas a prolongar sua vida ativa e produtiva, a continuar participando da sociedade com serviços on line mais acessíveis e a desfrutar durante mais tempo de uma melhor qualidade de vida e melhor saúde. É necessário lembrar, ainda de acordo com o documento, que "os europeus mais idosos são também importantes consumidores, possuindo bens que superam os três bilhões de euros". O mesmo ocorre nos Estados Unidos, onde a maior parte da economia americana está sob controle de pessoas com mais de 75 anos. E nos Estados Unidos os idosos estão se organizando em força eleitoral e já são maioria no Congresso, comprometendo-se a votar projetos que beneficiem diretamente esse segmento da população (Thurow,1997).

O Plano de Ação que integra o Programa da UE "Envelhecer bem na Sociedade da Informação" pretende "aumentar a sensibilização e criar consenso através da cooperação dos interessados, incluindo um portal de internet sobre melhores práticas; acelerar a aceitação das novas tecnologias através, por exemplo, de um conjunto de projetos-piloto e de um sistema de prêmios europeus para lares inteligentes e para aplicações que favoreçam uma vida independente; impulsionar a pesquisa e a inovação, apoiando o surgimento de produtos, serviços e sistemas inovadores baseados nas TICs, destinados aos idosos europeus, cada vez mais numerosos".

Todos esses dados revelam que os meios de comunicação, em todo o mundo, precisam se voltar, com atenção, para este segmento de público que se faz cada vez mais importante entre os consumidores de informação. A grande pergunta é se os jovens atualmente empenhados na formação acadêmica para o futuro desempenho do jornalismo estão sendo conscientizados, preparados, sensibilizados para o cumprimento dessa nova pauta. Afinal, o envelhecimento não pode ser visto como um "modismo", um fenômeno "de momento". A opção, para todas as pessoas, incluindo os jovens, não é escolher entre "sim" ou "não" nessa questão. Portanto, o jovem que hoje convive com a presença do idoso na própria família, ao frequentar a casa dos amigos, no ambiente de estudos, no comércio, nas ruas, nos meios de comunicação, nas manifestações de todo tipo, sabem que isso se tornará cada vez mais frequente, como indicam as estatísticas, e sabem também que esse será o seu mundo futuro. A característica das questões eminentemente sistêmicas como esta é que todos estão imbricados, de um modo ou de outro, na complexidade do mundo (e aprendemos com Edgard Morin e Max Weber que há vários mundos, várias realidades superpostas a serem consideradas pelos comunicadores), daí a importância ecológica do problema. Se não temos a opção de "não envelhecer" só nos resta a opção de "envelhecer bem". Por isto a questão do idoso deve ser tratada, nos estudos e práticas de comunicação, não com pieguice, paternalismo ou comiseração, mas com a dignidade e o respeito que o fato merece. Assim, não se deve tolerar qualquer tipo de discriminação dos meios de comunicação ou da sociedade em relação aos idosos. O Brasil inova nessa matéria com a criação do Estatuto do Idoso que protege os direitos da pessoa idosa e pune a discriminação. Mas ainda não há, no país, uma cultura de respeito aos "maiores", para usar o carinhoso termo espanhol, como ocorre em países orientais, caso do Japão e Índia, por exemplo. Tanto assim que o próprio Estatuto cobra dos empresários de mídia um espaço próprio para a terceira idade, mas isto é, praticamente, ignorado.

Do mesmo modo que a preparação dos futuros jornalistas para lidar com temas ambientais ainda é precária no Brasil, pois só algumas universidades adotam essa questão como matéria disciplinar nos cursos de Comunicação, também é escassa e quase inexistente a preocupação em preparar os comunicadores para a pauta do envelhecimento demográfico. Mas alguma coisa já está surgindo e um exemplo é o caso das Universidades Abertas à Terceira Idade que podem ser um instrumento de aplicação da Teoria do Empoderamento ou do Capital Social na medida em que preparam o idoso para uma vida social ativa e plena. Nesse particular, a Universidade de Sevilha tem uma contribuição a oferecer, como veremos a seguir. 


\section{Empoderamento na Universidade}

Na cantina da Faculdade de Comunicação da Universidade de Sevilha, na Isla de la Cartuja, os alunos da "Aula de la Experiencia" sentam-se junto com os jovens da graduação para tomar café, comer um "pão na chapa" e bater papo. Cabelos desgrenhados com cabelos prateados, calças jeans rasgadas com vestidos comportados, mochilas rotas com bolsas reluzentes.... não dá para distinguir quem está falando o que na alegre tagarelice do ambiente nessa cantina que parece o "escenário" do futuro e possível mundo de convivência entre diferenças e alteridades. Mas isto não ocorre por acaso. Acontece o mesmo no serviço de xerox, na secretaria, nos corredores, nas palestras do auditório... O Programa Universitário de Mayores da Universidade de Sevilha recomenda aos coordenadores de curso que promovam essa benéfica integração, embora os alunos da terceira idade tenham seu próprio curso, com matérias específicas e didática própria. A preocupação é não transformar a Universidade Aberta à Terceira Idade (como se diz no Brasil) em um "gueto", como se fosse um corpo estranho dentro do ambiente universitário.

Na abertura do Curso 2007/2008, da Aula da Experiência, na Faculdade de Comunicação da Universidade de Sevilha, o decano, professor Francisco Sierra Caballero, lembrou que "ser idoso não é ser triste. É uma oportunidade de aprender mais, enquanto tantos outros, pelos mais variados motivos, não tiveram esta oportunidade". Ele pediu que os alunos fossem disciplinados na participação em classe para aproveitarem bem o curso, no qual estudariam matérias divididas em oito campos temáticos: Ciências da Terra e do Meio Ambiente, Biosanitárias, Geografia e História, Antropologia, Psicologia e Comunicação, Língua e Literatura, Ciências Jurídicas e Ciências Econômicas. O curso também inclui um programa de voluntariado sociocultural para todos os 2.800 alunos da Aula da Experiência que a Universidade de Sevilha administra há 12 anos em seus campus da capital da Andaluzia (Sevilha) e em 9 centros do interior (para facilitar o acesso de todos os idosos).

Para Sierra Caballero, "a velhice começa quando as recordações pesam mais que a esperança, por isto não devemos perder a oportunidade de manter acesa a esperança, reconstruindo, permanentemente, a vida, valorizando a experiência acumulada, pois uma sociedade que não cultua a sua memória histórica condena a cidadania ao ostracismo e não progride". Lembrou ainda que a universidade não pode se ater apenas ao ensino objetivo, mas também deve contemplar os conteúdos que tratam da própria vida, e que, sendo pública, tem o dever de se colocar à disposição da sociedade, por isto, "os alunos da Aula da Experiência devem sentir-se bem na universidade, usufruindo de todos os espaços e serviços com os mesmos direitos dos demais alunos". Mas ele afirmou, ainda, que "muitas vezes também precisamos aprender a esquecer, a ser tolerantes, a reconhecer nossas limitações, mesmo quando temos plena consciência de nossos saberes. Há ocasiões na vida em que aprendemos mais esquecendo que lembrando", numa clara referência a eventuais problemas que podem ocorrer durante um curso universitário. E finalizou: "Este espaço é seu. Bem vindos".

Dias depois, naquele mês de setembro de 2007, foi ministrada por Ignácio Ramonet, no mesmo auditório "Manuel Chaves Nogales", igualmente lotado, também presidida pelo decano, a aula inaugural da Graduação. A relação entre as duas atividades acadêmicas é citada aqui apenas para mostrar como a direção da escola dá aos alunos da terceira idade o mesmo tratamento que dá aos alunos da graduação. Por isto a integração é visível no campus da Faculdade de Comunicação.

Reinserindo seus ex-alunos da terceira idade em ambientes de trabalho na Andaluzia, estimulando a cooperação com o poder público municipal para a prática de exercícios, colaborando com o programa do governo socialista de apoio ao turismo para os maiores, a Universidade de Sevilha contribui, de modo significativo, com a melhoria da auto-imagem das pessoas idosas e faz crescer o capital social dentro do grupo. Assim, a "Aula de la Experiencia" resulta como excelente exemplo de empoderamento que a Universidade pode e deve promover na sociedade, principalmente por ser pública e, portanto, por ser 
mantida pela sociedade, e por estimular o contato entre os idosos e os futuros jornalistas.

A aparição das Universidades de Maiores no mundo é relativamente recente, como demonstra o fato de que a primeira foi fundada em Toulouse (França) em 1973 pelo professor Pierre Vellas. Esse evento tornou-se um fenômeno social, embora tenha demorado a alcançar a relevância merecida, inclusive na própria França, onde esse movimento teve o maior êxito. Mais tarde se estende aos países francófonos e, posteriormente, aos demais países industrializados (VELÁZQUEZ, 2006: 11). Em 1980 a França já contava com 50 Universidades de Maiores e por todo o mundo surgiu pelo menos uma a cada mês, segundo o geriatra Manuel Velázquez Clavijo, coordenador da Aula da Experiência da Universidade de Sevilha, autor de livros a respeito. Ele dá mais detalhes: "Essas universidades surgem, inicialmente, com a intenção de proporcionar à pessoa maior um lugar na sociedade e recuperar sua dignidade. Com este objetivo, inicialmente se encaminharam para a formação, sobretudo em Gerontologia Social e para a pesquisa em temas relacionados com a saúde, a psicologia, a sociologia e a economia”.

A evolução mundial dessa iniciativa universitária passou, segundo Lemieux (2006) por três momentos históricos: Primeira Etapa, com serviços educativos concebidos como programas culturais de tempo livre, com a finalidade de entreter e favorecer as relações sociais; Segunda Etapa, com atividades educativas para a participação e melhoria dos conhecimentos, com a intervenção dos maiores em problemas sociais reais; e Terceira Etapa, de programas educativos regulares, com plano de estudos próprio, com todas as características do ensino superior e, geralmente, propostos a partir das Ciências da Educação.

Conforme Stadelhofer (apud VELÁZQUEZ, 2006: 14), existem estudos universitários para as pessoas idosas em todos os países europeus, a maioria dos quais conectados através de redes nacionais, como: a Associação Internacional das Universidades da Terceira Idade (fundada em 1975, http:/www.aiuta.asso.fr), que orienta na fundação e desenvolvimento das Universidades Abertas à Terceira Idade, promovendo o contato científico entre os membros e coordenadores; a Tirad Age Learning International Studies (Talis) [Estudos Internacionais de Formação da Terceira Idade], que tem como objetivo fortalecer o intercâmbio de especialistas na área; a European Federation of Older Students at Universities (Efós) [Federação Européia de Estudantes Maiores Universitários], que promove o contato entre os estudantes da terceira idade de toda a Europa; a European Network Learning in Later Life (Lill) ]Rede Européia de Educação Permanente de Pessoas Adultas], criada na conferência de Ulm, em 1996, como uma plataforma de informação e comunicação na internet (http:/www.uni-ulm.de/lill) para a terceira idade e que convoca reuniões periódicas em forma de conferência, oficinas etc.

A sigla espanhola de Programa Universitário para Mayores resulta estranha quando reproduzida em português, mas, segundo o professor Velázquez, os PUM encontram plena justificativa na necessidade de integração das pessoas maiores na sociedade e isto pode ser feito a partir da área acadêmica:

A integração dos maiores na Universidade deve ser abordada a partir da perspectiva da mudança das universidades em seu processo irreversível de democratização. Afortunadamente passamos de uma universidade elitista a uma universidade de massas; de uma universidade dirigida ao academicismo a uma universidade com três grandes funções: profissionalização, pesquisa e extensão cultural; de uma universidade dirigida só a jovens a uma universidade para todas as idades; de uma universidade fechada a uma universidade aberta a todos os projetos da sociedade do conhecimento (VELÁZQUEZ, 2006: 15).

Um debate desenvolvido na Universidade de Navarra em junho de 1999 sobre Demografia e Universidade revelou que até 2015 o grupo etário compreendido entre 20 e 29 anos, na Europa, terá uma redução de 11 milhões de pessoas (-20\%) enquanto o grupo compreendido entre 50 e 64 anos aumentará em 16,5 milhões de pessoas (+25\%). Isto significa, ainda segundo Velázquez (2006: 17), que serão as 
pessoas com mais de 50 anos que contribuirão, nos próximos anos, para manter boa parte das estruturas econômicas e de financiamento da própria universidade, sem contar a dívida social que as universidades já têm, presentemente, com a sociedade.

Diante da importância social das Universidades Abertas à Terceira Idade, não é possível compreender porque a mídia dá tão pouco destaque a essa formação, pelo menos no Brasil, onde tudo o que se refere ao idoso é visto como tema de segunda importância, "coisa de aposentados", "pessoal do INAMPS" (Instituto Nacional de Assistência Médica e Previdência Social). Também não se entende porque este tema não é tratado entre os futuros jornalistas que atualmente estão nos bancos universitários.

A Universidade de Sevilha também conta com um programa de integração entre jovens e idosos que poderia ser imitado em muitas cidades brasileiras. Trata-se de um projeto de voluntariado através do qual pessoas idosas podem solicitar a companhia de um estudante de Comunicação para não passarem a noite sozinhas. Maiores detalhes podem ser obtidos no Serviço de Atendimento à Comunidade Universitária (SACU), pelo e-mail sacuunidas@us.es ou no site da Universidade de Sevilha.

Não se pode encerrar este artigo sem lembrar a importante contribuição da Universidade de São Paulo (USP) e da Universidade Estadual Paulista (UNESP), na implantação da Universidade Aberta à Terceira Idade, a exemplo do que vem ocorrendo em várias outras universidades, inclusive particulares, destacando-se o curso de Gerontologia da Pontifícia Universidade Católica de São Paulo (PUC-SP), além do site "Portal do Envelhecimento" coordenado pela professora Beltrina Cortes (www.portaldoenvelhecimento.com.br). Na UNESP, sob supervisão da Pró-Reitoria de Extensão Universitária (PROEX), a UNATI existe há 16 anos em todos os campi da Universidade espalhados por todo o Estado de São Paulo, prestando relevantes serviços à sociedade.

\section{Conclusão}

Vimos neste artigo que as técnicas de empoderamento podem contribuir significativamente para a inclusão dos indivíduos e dos grupos sociais. Também vimos que o empoderamento faz crescer o nível de capital social da comunidade, levando a uma participação cidadã mais efetiva. Consideramos que os meios de comunicação têm importante contribuição a dar a este respeito e registramos a possibilidade de se produzir empoderamento a partir dos investimentos nas Tecnologias de Informação e Comunicação (TIC). Finalmente apresentamos o caso das Universidades Abertas à Terceira Idade como exemplo prático de aplicação das técnicas de empoderamento que merecem mais cobertura da mídia. O que queremos chamar atenção, entretanto, é para o pouco destaque que os meios de comunicação dão à questão do envelhecimento demográfico e para a falta de interesse dos cursos de Comunicação Social em preparar os futuros jornalistas em temáticas de cunho ambiental e de ecologia humana, como no caso da visibilidade dos idosos na sociedade, através da mídia.

\section{Bibliografia:}

ABRIL, Gonzalo. "El séptimo dia - notas sobre la comunicación en la era digital". In: BERNAL, Manuel (org.) Revista Científica de Información y Comunicación-1. Sevilha, Secretariado de Publicaciones de la Universidad de Sevilla, 2003.

BOURDIEU, Pierre. "Formas de Capitais". In: JC RICHARDS (org.). Handbook de Teoria e Pesquisa de Sociologia da Educação. New York: Greenwood Press, 1983. 
BOURDIEU, Pierre. O Poder Simbólico. Lisboa/Rio: Difel/Bertrand Brasil, 1989.

BOOKMAN, A. Starting in our own backyards. How working families can build community and survive the new economy. New York: Routledge, 2004.

CAPRA, F. Uncommon wisdom: Conversations with Remarkable People. New York: Simon and Schuster, 1988.

COLEMAN'S, J.C. “Capital social na criação de capital humano”. American Journal of Sociology n. 94, 1988. p. S95-S120.

COLEMAN'S, J.C. Foundations of Social Theory. Cambridge: Mass/Harvard University Press, 1994.

DAWN - DEVELOPMENT ALTERNATIVES WITH WOMEN FOR A NEW ERA. Development, Crisis and Alternatives Visions: Third World Women Perspectives. Delhi, 1985.

DURSTON, J. Qué es el capital social comunitário?. Santiago de Chile: CEPAL - Série Políticas Sociales, 2000.

EVANS, P. "Governenment Action Social Capital and Development: reviewing the Evidence on Synergy”. World Development. Vol. 24, n. 6, 1996. p. 1119-1132.

FREIRE, P. Pedagogia do Oprimido. Rio: Paz e Terra, 1980.

GRANOVETTER, M. "Economic action and the social structure: the problem of embeddedness". 1985.

LAPE, F. M. and DUBOIS, P. Quickening of America: Rebuilding our Nation Remaking our Lives". San Francisco: Jossey - Bass, 1994.

LEMIEUX, A. "Los programas universitários para mayores. Enseñanza e investigación”. Ministerio de Trabajo y Asuntos Sociales. (IMERSO). In VELÁZQUEZ, M. "Reflexiones sobre los Progamas Universitarios de Mayores - Una Visión desde la Práctica en el Aula de la Experiencia de la Universidad de Sevilla". Sevilla: Secretariado de Publicaciones de la US, 2006.

MCLAUGHLIN, C.; DAVIDSON, G. Spiritual Politics: changing the world from the inside out. New York: Ballantine, 1994.

MONTERO, M. Teoria y Pratica de la psicologia comunitaria. Buenos Aires: Paidós, 2003.

PUTTNAM, R. D. Making Democracy Work. Civic Traditions Modern in Italy. Princeton, NJ: Princeton University Press, 1993.

PUTTNAM, R. D. "Bowling alone: America's Declining Social Capital”. Journal of Democracy 6: 1 Jan 1995. p. 65-78.

PUTTNAM, R. D. "Bowling alone: The collapsy and revival of American Community". New York: Simon and Schuster, 2000.

ROMANO, J. O.; ANTUNES, M., (orgs.). Empoderamento e direitos no combate à pobreza. Rio: 
Actionaid, 2002.

SEMPERE J.; RIECHMENN, J. Sociologia y Medio Ambiente. Madrid: Editorial Síntesis, 2000.

SIERRA, Francisco. Introdución a la teoria de la comunicación educativa. Sevilla: MAD, 2000.

SIERRA, Francisco; MORENO, Javier (orgs.). Comunicación y Desarrollo en la Sociedad Global de la Información - Economia, Política y Lógicas Culturales. Sevilla: Edición Universidad de Sevilla, 2004.

SIERRA, Francisco. Comunic@rte - Guia de Comunicación Solidaria. Sevilla: Junta de Andalucía. Consejeria para la Igualdad y Bienestar Social. Delegación Provincial Sevilla / Universidad de Sevilla Facultad de Comunicación, 2006.

SILVA, Carmen; MARTINEZ, Maria Loreto. "Empoderamento: Proceso, Nivel y Contexto". Santiago de Chile: Revista Psyque/Pontificia Universidad Católica de Chile, 2004.

SKOCPOL, T. Diminished Democracy. Norman, Oklahoma: University Oklahoma Press, 2003.

SPEER, P. W.; HUGHEY, J. "Community organizing: Ecological route to empowerment and power". American Journal of Community psychology, 23 (5), 1995. p. 729-764.

THUROW, Lester C. O Futuro do Capitalismo - Como as forças econômicas moldam o mundo de amanhã. Trad. de Nivaldo Montingelli Jr. Rio de Janeiro: Rocco, 1997.

VELÁZQUEZ, M. Reflexiones sobre los Progamas Universitarios de Mayores - Una Visión desde la Práctica en el Aula de la Experiencia de la Universidad de Sevilla. Sevilla: Secretariado de Publicaciones de la US, 2006.

ZIMMERMAN, M. A.; RAPPORT, J.: "Citizen participation, perceived control and psycological empowerment”. American Journal of Community Psychology, 16, 1998. p. 725-750.

ZIMMERMAN, M. A. "Empowerment Theory". In: J. RAPPORT; E. SEIDMAN (Eds). Handbook of Community Psychology. New York: Kluver, 2000. p. 43-63.

\section{Notas:}

Este artigo faz parte dos estudos pós-doutorais na Facultad de Comunicación de la Universidad de Sevilla, entre setembro/2007 e março/2008, com supervisão do Prof. Dr. Francisco Sierra Caballero e com bolsa do Programa de Estágio de Pós-Doutorado no Exterior, da Pró-Reitoria de Pesquisa da UNESP, em convênio com a Fundação Banespa/Santander.

(1) Não se pode entender o Brasil sem ler Paulo Freire, diz o professor Francisco Sierra Caballero, da Faculdade de Comunicação da Universidade de Sevilha, estudioso da América Latina.

\section{Mini Currículo :}

Pedro Celso Campos, 60, é Coordenador do Curso de Jornalismo da Faculdade de Arquitetura, Artes e Comunicação da Universidade Estadual Paulista-FAAC/UNESP, campus de Bauru-SP. E-mail: pcampos@faac.unesp.br 